\title{
O PROFESSOR DE INGLÊS DE INSTITUTO DE LÍNGUAS, TRABALHO E CONSTITUIÇÃO PROFISSIONAL ${ }^{1}$
}

\author{
Gladys Plens de Quevedo Pereira de Camargo²
}

\begin{abstract}
RESUMO
Este trabalho está inserido na área de formação de professores de língua inglesa e foi realizado em um instituto particular de ensino de inglês. Objetivou investigar (1) a visão de professores de inglês sobre seu trabalho e o fenômeno da globalização e (2) sua auto-imagem e constituição profissional. As reflexões teóricas que guiaram esta investigação incluem a relação entre globalização e educação, a importância do papel do professor enquanto educador, a atitude do profissional diante da língua inglesa, gênero ou cultura profissional e fatores que exercem influência sobre o trabalho do professor. A coleta das informações foi feita por meio de um questionário, que foi respondido por vinte e duas professoras da instituição. A análise das respostas demonstra que as professoras investigadas têm total consciência da relação entre seu trabalho e globalização e da importância do seu papel na formação dos alunos-clientes, na medida em que são elas que os instrumentaliza para a comunicação com o mundo. Além disso, atribuem grande parte da sua constituição profissional às suas próprias experiências sobre aprender e ensinar inglês.
\end{abstract}

Palavras-chave: professor de inglês, instituto de línguas, globalização, auto-imagem, constituição profissional.

\section{INTRODUÇÃO}

O status atual da língua inglesa como língua internacional, língua franca ou "World English" tem sido bastante discutido por diversos autores (e.g., LLURDA, 2004; RAJAGOPALAN, 2005; RINVOLUCRI, 2005; entre outros). De língua nacional nos séculos XVI e XVII e imperial nos séculos XVIII e XIX, a língua inglesa transformou-se numa língua mundial a partir do século XX, sinônimo de poder e meio seguro de ascensão social (LE BRETON, 2005). No mundo todo, milhares de profissionais estão direta ou indiretamente envolvidos com a disseminação do inglês como língua estrangeira ou segunda língua e estima-se que 1,5 milhão de pessoas - 1/4 da população mundial - têm algum conhecimento de inglês (RAJAGOPALAN, 2005). Estamos certamente diante de um fenômeno educacional mundial sem precedentes.

\footnotetext{
${ }^{1}$ Este trabalho foi elaborado como parte da disciplina "Fatores institucionais e atuação docente no ensino de línguas” ministrada pelas professoras doutoras Telma Gimenez e Vera Cristóvão do Programa de Pós-graduação em Estudos da Linguagem da Universidade Estadual de Londrina (UEL).

${ }^{2}$ Mestranda do Programa de Pós-graduação em Estudos da Linguagem da Universidade Estadual de Londrina (UEL).
} 
No Brasil o ensino de língua inglesa se dá em seis cenários diferentes:

1. no ensino regular público;

2. no ensino regular privado, com inglês normalmente na grade curricular;

3. no ensino regular privado, com inglês normalmente na grade curricular e curso de inglês no contra-turno terceirizado a um instituto de línguas;

4. no ensino regular privado, com inglês da grade curricular terceirizado;

5. ensino em institutos de línguas, que podem ser escolas independentes, franquias ou os chamados centros binacionais geralmente americanos ou britânicos; e

6. através de professores autônomos.

Essa diversidade de contextos, considerados como fenômenos socialmente constituídos, sustentados interacional e temporalmente (GOODWIN e DURANTI, 1992), suscita diferentes questões - entre elas a relação entre o local e o global, representada pelo trabalho do professor de língua inglesa como língua estrangeira em qualquer contexto possível, pela abrangência e diversidade do objeto de ensino, e pela própria constituição do professor como profissional engajado na disseminação dessa língua.

Não há estatísticas disponíveis, mas poderíamos facilmente supor que a maioria desses professores é o que muitos autores chamam de "não-nativos". Apesar de considerado ultrapassado ou de difícil definição por alguns autores (e.g., MEDGYES, 1994; RAJAGOPALAN, 2005 - afinal, o que é exatamente um falante nativo?), esse termo ainda é usado para estabelecer diferenças entre os nascidos ou não em países onde se fala a língua inglesa.

Inegavelmente, no mundo todo o ensino de língua inglesa está muito mais nas mãos de professores não nativos do que de nativos, o que vem ao encontro do fato já bastante conhecido de que o número de falantes não nativos de língua inglesa é muito maior do que o número de falantes nativos. Como conseqüência dessa aceitação gradual do inglês como língua franca, observamos a diminuição da importância do papel dos professores nativos com relação ao estabelecimento de princípios e normas sobre os quais o ensino da língua inglesa se baseará no futuro (LLURDA, 2004).

Com essas questões em mente, elaboramos a pesquisa que aqui relatamos. Seus objetivos foram (1) investigar a visão de professores de inglês sobre seu trabalho e o fenômeno da globalização, e (2) identificar sua auto-imagem como profissionais e como se constituem ou se constituíram como tal. 
Apresentamos a seguir algumas reflexões teóricas que embasaram este trabalho, o contexto da pesquisa e a metodologia para coleta dos dados. Na seqüência, apresentamos a análise e interpretação dessas informações.

\section{REFLEXÕES TEÓRICAS}

A relação entre globalização e educação é uma questão polêmica e tem sido muito discutida por diversos pesquisadores. Segundo Morrow e Torres (2004), globalização é a intensificação de relações sociais mundiais que ligam comunidades distantes, de modo que os acontecimentos locais são moldados por eventos que ocorrem a muitas milhas de distância e vice-versa. Porém, a globalização é vista como algo que obscurece os limites nacionais, altera solidariedades dentro dos Estados e entre eles, e afeta profundamente a constituição de identidades nacionais e grupos de interesse. Para os autores, os conflitos e incertezas da globalização refletem-se na educação na medida em que há disjunção entre o local e o global, reforçando a urgência de se repensar as políticas educacionais como um todo.

Cameron (2002), por sua vez, preocupa-se com os efeitos da globalização na língua inglesa e no seu uso, e levanta questões de legitimidade do ensino de conhecimentos e habilidades determinados pelas culturas dominantes (americana ou britânica), questionando os interesses que subjazem às escolhas de conteúdo. Na visão de Suarez-Orozco e Qin-Hillard (2004), no entanto, a chamada globalização permanece um território inexplorado onde predominam a diferença e a complexidade. Eles reconhecem a importância do trabalho interdisciplinar e a necessidade de se educar para a globalização.

Diante das questões levantadas por esses autores, é imprescindível pensarmos também na função do professor de inglês nesse contexto. Volpi (2001), num estudo com professores de diversas disciplinas, sustenta que eles têm papel definitivo na preparação das pessoas para a vida e que devem atender a funções sociais mais abrangentes que vão muito além da mera transmissão de conhecimentos. Na mesma linha, Osler (2005) afirma que os professores de línguas têm uma posição privilegiada para contribuir significativamente para uma educação voltada para a cidadania democrática, e que a sala de aula de línguas é o lugar perfeito para a condução à cidadania cosmopolita, que pressupõe um entendimento mais amplo da identidade nacional e conexões entre experiências diárias nas comunidades em níveis nacional e global. Na sua visão, bons professores devem necessariamente ser cidadãos cosmopolitas. 
Outro fator importante levantado por alguns autores refere-se às diferentes posturas do professor de língua inglesa perante a língua que ensina. Um estudo realizado por Freitas (2003) identificou três posturas diferentes que influenciam diretamente o trabalho do professor: a supervalorização da língua inglesa e tudo que se relaciona a ela; a identificação da língua inglesa como símbolo do imperialismo americano; e a identificação da língua inglesa como língua franca e instrumental. Leffa (2005) também aborda a questão do papel do professor de língua inglesa perante a língua e seu ensino, e afirma que sua atitude varia de alienada, por ver a língua como algo neutro e apolítico, a consciente, ao atuar como um agente politicamente engajado.

O fato de que a língua inglesa é ensinada no mundo todo em diferentes contextos e por uma variedade imensa de profissionais remete-nos ao que alguns pesquisadores chamam de 'culturas de ensinar’. Partindo do princípio de que ensinar é uma prática social, Nesbit (2000) define tais culturas como práticas e comportamentos que são repetitivos e limitados, incluindo as experiências de professores e alunos, assim como as influências sociais que ajudam a moldá-las. Citando Feinam-Nemser (1986 apud NESBIT, 2000), o autor diz que as culturas de ensinar estão incorporadas nas crenças relativas ao trabalho e ao conhecimento que os professores compartilham. Tais crenças referem-se a maneiras apropriadas de agir no trabalho, aspectos recompensadores do ensino, e conhecimentos que permitem aos professores executar seu trabalho. A origem de tais culturas, segundo Hargreaves (1994 apud NESBIT, 2000), residiria nas tradições, nas crenças, nos valores, nos costumes e nas formas pressupostas de desenvolver o trabalho entre comunidades de professores que têm que lidar com demandas e limitações semelhantes.

O termo 'cultura profissional' surge no trabalho de alguns autores como Saujat (2004), que afirma que tal cultura se baseia em seis critérios: (a) numa base de conhecimentos ligados ao agir profissional; (b) numa prática adaptada em situação complexa; (c) numa capacidade de dar conta de suas próprias competências e atos; (d) numa autonomia e numa responsabilidade pessoal no exercício de suas competências; (e) numa adesão a normas coletivas constitutivas da identidade profissional; e (f) num pertencimento a um grupo que desenvolve estratégias de promoção e de valorização. Para o autor, esses critérios permitem a descrição de estilos profissionais que se subdividem em três dimensões interdependentes que são o estilo pessoal do professor, seu estilo relacional-interacional e seu estilo didático.

Faïta (2004), por sua vez, menciona 'gêneros de atividade', e utiliza Schwartz (2001 apud FAÏTA, 2004) para definir atividade como o modo próprio de cada um reconstituir sua tarefa profissional. Essa visão é muito próxima da visão de Nesbit, na medida em que 
considera que a origem desse gênero e suas normas está na "multiplicação das atividades semelhantes que reúnem os membros do grupo e que acabam na produção daquilo que lhe é próprio em matéria de formas de agir e de modos de avaliação dessas formas” (FAÏTA, 2004, p.62).

Souza-e-Silva (2004) e Lousada (2004) também abordam a questão do gênero profissional baseando-se na definição de Clot et al. (2001 apud LOUSADA, 2004). Essas autoras afirmam que gêneros profissionais são os pressupostos sociais da atividade em curso, uma memória impessoal e coletiva que se traduz em maneiras de agir e que constituem um repertório de ações adequadas ou inadequadas para a situação.

Sendo assim, poderíamos considerar que a cultura de ensinar ou gênero profissional existe em dois níveis. O primeiro, mais abrangente, composto de elementos válidos a qualquer contexto de ensino e profissional ligado a ele. O segundo, mais específico, composto por singularidades da experiência profissional que surgem devido à diversidade humana, ou seja, as diferentes influências e experiências que constituem cada professor em todo o mundo.

Amigues (2004) afirma que a atividade do professor é influenciada por diferentes fatores e a vê como ponto de encontro de várias histórias. Na opinião de Saujat (2004), o professor alcança a maestria no ensino por meio de reflexões baseadas em imagens de casos interiorizados através da experiência. Além disso, ele sustenta que ensinar é um ofício dúplice, pois produz efeitos tanto nos alunos quanto nos professores.

Alguns autores, a partir de suas pesquisas, apontam possíveis fontes de influência no trabalho do professor de línguas. Zeichner et al. (1987), investigando as influências no desenvolvimento do conhecimento prático do professor, enfatizam que não há consenso entre os autores quanto aos vários agentes socializantes e mecanismos que atuam nesse processo. Porém, seus estudos indicam três explicações alternativas para a constituição do professor: (1) as influências pré-treinamento, que se referem à tendência natural de ensinar do ser humano e à sua biografia; (2) as influências da formação pré-serviço, exercidas pelo currículo explícito e implícito dos cursos de fundamentação e métodos educacionais, e pelas práticas de ensino; e (3) as influências da experiência escolar, exercidas por todos os elementos que compõem o local de trabalho do professor.

Jordell (1987), por outro lado, em sua análise sobre influências estruturais e pessoais na socialização de professores iniciantes, sugere que as influências estruturais provenientes da instituição e da sociedade exercem influência maior do que as memórias que o professor tem de experiências como aluno. 
Assumindo que as influências que constituem o professor se revelam por meio de suas crenças, expressas conscientemente ou não, convém mencionarmos que Gimenez (1994), em seu estudo sobre crenças de professores de inglês no Brasil, também apresenta uma estrutura tríplice de possíveis fontes para tais crenças: suas experiências como aluno, suas experiências como professor e sua formação (cf. Zeichner et al. acima).

As reflexões teóricas sobre os cinco temas abordados acima - a relação entre globalização e educação, a importância do papel do professor de inglês na formação do seu aluno, a postura do professor diante da língua que ensina, questões relativas ao gênero ou cultura profissional e fatores que podem influenciar o trabalho do professor de inglês - serão utilizadas na análise e interpretação dos dados obtidos nesta investigação após a apresentação dos aspectos metodológicos em questão.

\section{CONTEXTO DA PESQUISA}

O contexto escolhido para essa investigação foi um instituto particular de língua inglesa tradicional na cidade, com fortes laços com a cultura britânica, que tem como públicoalvo crianças, jovens e adultos de classe média e alta, na sua maioria.

Participaram desta pesquisa vinte e duas professoras da instituição, das quais 68\% (15 professoras) não têm formação em Letras, 23\% (5 professoras) têm formação em Letras e 9\% (2 professoras) estavam cursando Letras naquele momento. Seu tempo de experiência como professoras de língua inglesa varia entre 1,5 ano e 20 anos.

Esta investigação foi realizada no período de outubro a dezembro de 2005.

\section{METODOLOGIA E INSTRUMENTO PARA COLETA DE DADOS}

O instrumento escolhido para ser utilizado nesta investigação foi o questionário por proporcionar acesso rápido e fácil aos profissionais, independentemente do seu horário de trabalho. Os 25 professores da instituição foram abordados pessoalmente por esta pesquisadora durante o intervalo de suas aulas. Numa breve conversa, ouviam o objetivo do trabalho, recebiam orientações sobre a capa do questionário (garantia de sigilo e pedido de autorização - vide Anexo), sobre o questionário propriamente dito (vide Anexo), e eram convidados a participar, levando o questionário consigo e devolvendo numa data combinada 
(aproximadamente duas semanas depois). Todos os 25 professores abordados aceitaram colaborar, porém somente 22 professoras devolveram os questionários em tempo hábil para a elaboração deste trabalho.

O questionário foi elaborado com cinco questões, sendo que as questões 1 e 3 focalizaram o primeiro objetivo - relação entre trabalho e globalização - e as questões 2, 4 e 5 concentraram-se no segundo objetivo - auto-imagem e constituição profissional.

Os questionários coletados foram colocados em ordem aleatória e identificados numericamente (P-1 a P-22) para que excertos de suas justificativas pudessem ser utilizados neste artigo.

\section{ANÁLISE E INTERPRETAÇÃO DOS DADOS}

A seguir reproduzimos as questões do questionário, e apresentamos os dados obtidos e algumas interpretações.

Questão 1: Na sua opinião, existe alguma relação entre o tema 'globalização’ e sua prática de sala de aula?

Vinte e uma professoras (95 \%) responderam que acreditam haver relação entre o tema globalização e sua prática docente, corroborando as afirmações de Morrow e Torres (op.cit.). As justificativas apresentadas por elas se resumem basicamente em três aspectos:

1. a língua inglesa está em todo lugar - é o que de fato move a globalização - e o aluno dever ser preparado para usá-la onde estiver; é uma necessidade pessoal e profissional;

2. tudo o que acontece no mundo influencia professores e alunos, e é preciso estar apto a discutir atualidades;

3. a facilidade geral de acesso a informações cria a necessidade de se estar bem informado e atualizado em termos de ferramentas pedagógicas.

As professoras parecem confirmar a pesquisa de Volpi (op.cit.), na medida em que expressam consciência do papel que desempenham na disseminação da língua mais falada do mundo, e parecem estar cientes de que são agentes e participantes do processo de formação e desenvolvimento de seus alunos quando afirmam a importância de estarem atualizadas e tratarem de atualidades e temas culturais em classe. 
Os alunos se envolvem mais com temas atuais e a globalização é um deles. $(\mathrm{P}-10)$

Alunos e professores precisam estar bem informados e aptos a discutir assuntos e fatos que ocorrem no mundo atualmente (P-15)

O ensino de língua inglesa é um exemplo básico de globalização, assim como as discussões sobre cultura e o uso da internet em algumas aulas (P-

Não há menção de conflito entre cultura local e estrangeira, sugerindo talvez uma postura apolítica (Leffa, op.cit.). As professoras parecem se considerar como pontes que ligam seus alunos ao mundo, ou como janelas pelas quais seus alunos podem enxergar além dos seus limites geográficos.

O idioma inglês é ferramenta crucial na globalização. As aulas têm que visar o mundo real (P-5)

Como professora procuro mostrar ao aluno como utilizar a língua inglesa em qualquer lugar do mundo em que ele esteja (P-12)

(Existe) a necessidade de se mostrar mais e mais do mundo ao aluno (P-17)

Considerando-se que, na sua maioria, os alunos que freqüentam a instituição em que a pesquisa foi feita têm bom poder aquisitivo, e conseqüentemente acesso à internet e muitas vezes a viagens internacionais, a preocupação de algumas professoras com relação a se manterem atualizadas sobre o que acontece ao redor do mundo parece indicar que elas acreditam que isso seja um diferencial que mantém o aluno interessado e motivado a freqüentar as aulas.

Os alunos estão conectados com o mundo e a nossa aula também deve estar $(\mathrm{P}-21)$

O ensino da língua inglesa é um exemplo básico de globalização, assim como as discussões sobre cultura e o uso da internet em algumas aulas (P-22)

As justificativas apresentadas por essas professoras indicam que elas vêem o ensino da língua inglesa como língua franca e instrumental, como um meio de possibilitar comunicação, acesso e conhecimento aos alunos. Essa visão traz implicações importantes para o trabalho em classe, fazendo com que as professoras procurem abordar o conteúdo de forma 
contextualizada, estabelecendo conexões com os fatos e acontecimentos do dia-a-dia e visando desenvolver a capacidade comunicativa do aluno. Temos aqui uma possível característica da cultura profissional dessas professoras.

Questão 2: Numere os fatores que, na sua opinião, influenciam de alguma forma seu trabalho como professor(a). Coloque 1 (mais importante); 2 (importante) ou 3 (menos importante).

As opções das professoras para cada item apresentado foram:

\begin{tabular}{|l|c|c|c|c|}
\hline \multicolumn{1}{|c|}{$\begin{array}{c}\text { Fatores que influenciam o } \\
\text { trabalho }\end{array}$} & $\begin{array}{c}\text { Mais } \\
\text { importante }\end{array}$ & Importante & $\begin{array}{c}\text { Menos } \\
\text { importante }\end{array}$ & $\begin{array}{c}\text { Não } \\
\text { assinalaram }\end{array}$ \\
\hline $\begin{array}{l}\text { As determinações da instituição em } \\
\text { que você trabalha }\end{array}$ & 7 & $\mathbf{1 3}$ & 1 & 1 \\
\hline O livro didático utilizado & 3 & $\mathbf{1 5}$ & 4 & 0 \\
\hline $\begin{array}{l}\text { Sua própria visão sobre o que é } \\
\text { aprender e ensinar inglês }\end{array}$ & $\mathbf{1 7}$ & 5 & 0 & 0 \\
\hline $\begin{array}{l}\text { Suas experiências anteriores como } \\
\text { estudante }\end{array}$ & $\mathbf{9}$ & 8 & 3 & 2 \\
\hline Sua formação universitária & 2 & $\mathbf{1 0}$ & 9 & 1 \\
\hline Os cursos que você já fez & 6 & $\mathbf{1 0}$ & 4 & 2 \\
\hline Os eventos dos quais já participou & 3 & $\mathbf{1 1}$ & 7 & 3 \\
\hline $\begin{array}{l}\text { Sua vivência em países de língua } \\
\text { inglesa }\end{array}$ & 5 & 6 & $\mathbf{8}$ & 1 \\
\hline $\begin{array}{l}\text { O que acontece à sua volta (na sua } \\
\text { cidade, no estado, no país, no } \\
\text { mundo) }\end{array}$ & 6 & $\mathbf{9}$ & 6 & 0 \\
\hline $\begin{array}{l}\text { Outros (1): O objetivo do aluno e sua } \\
\text { satisfação e independência com o } \\
\text { idioma }\end{array}$ & 1 & 0 & 0 & 0 \\
\hline $\begin{array}{l}\text { Outros (2): Trocar idéias com as } \\
\text { colegas }\end{array}$ & 0 & 1 & 0 & 3 \\
\hline
\end{tabular}

Tabela 1: Fatores que influenciam o trabalho docente na opinião das professoras.

Essa tabela nos mostra que as determinações da instituição e o livro didático foram considerados importantes por um bom número de professoras (13 e 15 votos respectivamente), enquanto que a própria visão sobre aprender e ensinar inglês foi votada como o fator que mais influencia o trabalho delas (17 votos). As experiências anteriores como estudantes foram consideradas como fator mais importante (9 votos) ou importante (8 votos). A formação universitária, por sua vez, foi considerada fator importante com 10 votos e menos importante, com 9 votos. Os cursos e eventos dos quais as professoras participaram foram considerados importantes (10 e 11 votos respectivamente), ao passo que a vivência em países de língua inglesa foi vista como menos importante (8 votos). Finalmente, os acontecimentos atuais foram julgados importantes por 9 pessoas. 
Portanto, a ordem de importância dos fatores influenciando o trabalho docente de acordo com as professoras investigadas seria:

1. Sua própria visão sobre o que é aprender e ensinar inglês;

2. O livro didático utilizado;

3. As determinações da instituição em que você trabalha;

4. Os eventos dos quais já participou;

5. Sua formação universitária e Os cursos que você já fez.

Esses dados nos fazem pensar no chamado efeito professor mencionado por Saujat (2004, p.6), relativo ao papel que os professores e sua forma de ensinar exercem na produção dos resultados escolares. Nessa concepção, o processo ensino-aprendizagem parece depender totalmente de cada professor, na medida em que são seus conceitos e crenças que norteiam seu trabalho e sua postura profissional. Sendo assim, as professoras deste estudo parecem se ver como profissionais com alto grau de autonomia e independência de atuação, negligenciando fatores sociais, políticos, econômicos e estruturais que, conforme os autores consultados, certamente influenciam suas práticas diárias.

Questão 3: O seu conhecimento sobre ensinar inglês seria útil em outro contexto educacional (outra escola, cidade ou outro país)?

Novamente, vinte e uma professoras (95 \%) disseram acreditar que seus conhecimentos sobre ensinar inglês seriam úteis em outro contexto educacional, que poderia ser outra escola, outra cidade, ou até mesmo outro país.

As justificativas indicam que as professoras acreditam na sua capacidade de adaptação, uma vez que dispõem do que consideram ser os princípios essenciais para ensinar língua inglesa, ou seja, o conhecimento lingüístico propriamente dito e conhecimentos didático-pedagógicos. Dessa forma, as professoras expressam que o domínio da cultura de ensinar e o desenvolvimento do estilo profissional as capacitam para desenvolverem seu trabalho onde for necessário, atribuindo à atividade de ensinar um caráter universal.

Independentemente de onde eu leciono, meus princípios continuam os mesmos. Claro que há variação no que tange às necessidades dos alunos (P-7) A teoria e os fundamentos permanecem os mesmos, e devem somente ser adaptados para cada situação (P-9) 
Algumas respostas também demonstram a confiança que as professoras depositam no poder e autonomia que conhecer e ensinar a língua inglesa lhes dá, demonstrando uma postura de identificação da língua inglesa como língua franca e instrumental.

Apesar da realidade em outro contexto ser diferente, uma pessoa bem informada se adapta fácil(mente) a outras realidades (P-1)

O conhecimento sempre pode ser aplicado de alguma forma em todo contexto (P-8)

As pessoas precisam entender inglês, está muito difícil viver sem ter algum conhecimento da língua (P-15)

Este conhecimento me proporciona uma visão do mundo mais abrangente que acaba influenciando nas minhas relações sociais (P-16)

Acho que sou altamente adaptável mas também tenho estilo próprio de relacionamento com os alunos, o que ajuda muito na adaptação (P-21)

Porque, mais do que ensinar, eu aprendo muito sobre relacionamentos interpessoais, diferentes modos de pensar e aprender (P-22)

As respostas dadas à Questão 3 confirmam a crença das professoras na sua autonomia profissional e capacidade de transferência e adaptação do conhecimento e experiência que possuem para qualquer contexto de trabalho. Poderíamos supor que, ao mencionarem uma possível adaptação a outros contextos, elas estejam levando em conta variáveis institucionais, sociais, econômicas, culturais e políticas que podem influenciar sua atuação em classe. Isso, porém, não fica claro nas afirmações das professoras.

Questão 4: Na sua opinião, quais são os conhecimentos mais importantes que devem ser dominados pelo professor de inglês, independentemente do seu contexto de trabalho? Coloque 1 (mais importante); 2 (importante) ou 3 (menos importante). 
A tabela a seguir mostra os resultados das respostas das professoras.

\begin{tabular}{|c|c|c|c|c|}
\hline $\begin{array}{l}\text { Conhecimentos mais importantes que } \\
\text { devem ser dominados pelos professores }\end{array}$ & $\begin{array}{c}\text { Mais } \\
\text { importante }\end{array}$ & Importante & $\begin{array}{c}\text { Menos } \\
\text { importante }\end{array}$ & $\begin{array}{c}\text { Não } \\
\text { assinalaram }\end{array}$ \\
\hline Metodologia & 13 & 8 & 1 & 0 \\
\hline Pedagogia e didática & 16 & 6 & 0 & 0 \\
\hline A língua inglesa propriamente dita & 17 & 3 & 2 & 0 \\
\hline Experiência prática em sala de aula & 10 & 11 & 0 & 1 \\
\hline Vivência em países de língua inglesa & 2 & 2 & 17 & 1 \\
\hline Outros (1): Conhecer o aluno como pessoa & 1 & 0 & 0 & 0 \\
\hline $\begin{array}{l}\text { Outros (2): Noções de pedagogia e } \\
\text { dinâmica de grupo }\end{array}$ & 0 & 1 & 0 & 0 \\
\hline
\end{tabular}

Tabela 2: Conhecimentos mais importantes que devem ser dominados pelo professor, na opinião das professoras investigadas.

O item “A língua inglesa propriamente dita” foi escolhido por 17 professoras como sendo o conhecimento mais importante a ser dominado pelos professores. Os aspectos didático-pedagógicos e metodológicos também foram considerados como mais importantes (16 e 13 votos respectivamente), o que talvez indique que, na visão delas, estes podem ser mais facilmente assimilados ou trabalhados uma vez que a questão lingüística esteja resolvida.

As experiências práticas em sala de aula foram julgadas como sendo importantes por 11 professoras. É interessante observar que 17 professoras escolheram "vivência em países de língua inglesa” como o conhecimento menos importante para a prática da profissão. A ausência deste tipo de conhecimento pode ser visto por elas como facilmente contornável quando os conhecimentos lingüístico, didático-pedagógico e metodológico são satisfatoriamente alcançados. Pode indicar também que a língua inglesa é vista pelas professoras como algo acima de questões culturais ligadas a limites geográficos, o que coincide com a visão de língua franca e símbolo de globalização expressa por elas na Questão 1.

Questão 5: Na sua opinião, quais conhecimentos foram predominantes para que você fosse selecionado(a) para trabalhar na instituição em que você está? (assinale quantos forem necessários) 
As opções mais assinaladas foram:

\begin{tabular}{|l|c|}
\hline $\begin{array}{c}\text { Conhecimentos determinantes para } \\
\text { contratação na opinião das professoras }\end{array}$ & Número de professoras \\
\hline Seu conhecimento metodológico & 13 \\
\hline Seu conhecimento didático-pedagógico & 21 \\
\hline Seu conhecimento de língua inglesa & 8 \\
\hline Suas experiências anteriores como professora & 8 \\
\hline Sua vivência em países de língua inglesa & 0 \\
\hline Outros? & \\
\hline
\end{tabular}

Tabela 3: Conhecimentos determinantes para contratação na opinião das professoras.

A escolha das professoras reforça a importância dada ao conhecimento lingüístico, já que a maioria (21 professoras) acredita ter sido esse o fator determinante na sua seleção para trabalhar na instituição. O conhecimento didático-pedagógico vem em segundo lugar, com 13 votos.

\section{CONSIDERAÇÕES FINAIS}

A partir de reflexões suscitadas pela leitura de diversos autores, pretendemos investigar a visão de um determinado grupo de professoras sobre a relação entre seu trabalho e globalização, identificar sua auto-imagem e como elas se constituem ou constituíram como profissionais de língua inglesa. O contexto desta investigação foi um instituto de língua inglesa, onde vinte e duas professoras responderam a um questionário composto de cinco questões.

As respostas obtidas indicam que a maioria das professoras do contexto investigado percebe claramente que seu trabalho diário está inserido num contexto maior e que sua atividade profissional está necessariamente ligada à globalização, na medida em que se torna imprescindível que elas estejam sempre atualizadas (em termos lingüísticos, didáticos, culturais e tecnológicos) para atender satisfatoriamente ao público-alvo com o qual trabalham. Dessa forma, tanto o foco central do trabalho - o aluno-cliente, quanto a instituição em que atuam exigem das professoras flexibilidade, comprometimento, envolvimento e criatividade no trabalho. Apesar de não perceberem, estas professoras desenvolvem seu trabalho nos moldes da flexibilização industrial e da customização de serviços numa era de alta 
competitividade, na qual a satisfação do cliente tem por objetivo gerar fidelização, que é essencial para a sobrevivência de uma instituição privada de ensino.

$\mathrm{Na}$ visão dessas professoras, a língua inglesa é algo que capacita e empodera, representa comunicação e acesso ilimitado a lugares e informações. Em nenhum momento, as professoras expressaram preocupações com imperialismo lingüístico ou submissão cultural de qualquer natureza, o que pode indicar, em primeiro lugar, que elas não percebem quaisquer conflitos ou ameaças à identidade lingüística-cultural própria e de seus alunos diante da presença quase onipotente da língua inglesa no seu dia-a-dia. Em segundo lugar, tal atitude pode indicar ausência de reflexão sobre os aspectos políticos que certamente permeiam o ensino de qualquer língua estrangeira em qualquer contexto educacional.

Quanto à sua constituição profissional, dezessete professoras acreditam que o fator que mais influencia seu trabalho é sua própria visão sobre ensinar e aprender inglês, seguido do livro didático (quinze votos) e das determinações da instituição em que trabalham (treze votos). Esses números fazem-nos refletir sobre a questão da importância do professor não nativo encarregado de ensinar inglês como língua estrangeira. Parece-me que, se seu trabalho é desenvolvido sob influência tão forte das suas experiências pessoais, a abrangência da formação do professor toma proporções imensas, pois todo tipo de trabalho pedagógico a que uma pessoa é exposta deveria então considerar o impacto profundo na constituição daquele futuro profissional (professor ou não) e no desenvolvimento de suas crenças sobre ensinar e aprender.

Finalmente, o domínio da língua inglesa como ferramenta de trabalho foi enfatizado por dezessete das vinte e duas professoras pesquisadas, e quase a totalidade (vinte e uma professoras) afirmou que foi selecionada para trabalhar naquela instituição devido aos seus conhecimentos lingüísticos.

Em suma, esta investigação revelou profissionais com auto-imagem bastante positiva. As professoras do contexto investigado expressam segurança e se consideram profissionais instrumentalizadas lingüística e didaticamente, vêem a língua inglesa como meio de ascensão social e comunicação com o mundo e têm consciência de que suas histórias pessoais exercem grande influência no seu trabalho. 


\section{REFERÊNCIAS}

AMIGUES, René. Trabalho do professor e trabalho de ensino. In: MACHADO, Anna Rachel.

(Org.) O ensino como trabalho: uma abordagem discursiva. Londrina: EDUEL, 2004. p.35-53.

CAMERON, Deborah. Globalization and the teaching of "communication skills". In: BLOCK, David; CAMERON, Deborah (Eds.) Globalization and language teaching. New York and London: Routledge, 2002. p. 67-82.

FAÏTA Daniel. Gêneros de discurso, gêneros de atividade, análise da atividade do professor. In: MACHADO, Anna Rachel. (Org.) O ensino como trabalho: uma abordagem discursiva. Londrina: EDUEL, 2004. p. 55-80.

FREITAS, Alice Cunha de. O ensino da língua inglesa no Brasil: mitos e crenças. In: FREITAS, Alice Cunha de; CASTRO, Maria de Fátima F. Guilherme de. (Orgs.) Língua e literatura - ensino e pesquisa. São Paulo: Editora Contexto, 2003. p. 97-108.

GIMENEZ, Telma Nunes. Learners becoming teachers: an exploratory study of beliefs held by prospective and practicing EFL teachers in Brazil. Unpublished PhD Thesis. UK: Lancaster University, 1994.

GOODWIN, Charles; DURANTI, Alessandro. Rethinking Context: an introduction. In: DURANTI, Alessandro; GOODWIN, Charles. Rethinking context - language as an interactive phenomenon. Cambridge: Cambridge University Press, 1992. p. 1-42.

JORDELL, Karl Øyvind. Structural and personal influences in the socialization of beginning teachers. In: Teaching and teacher education. Great Britain, v.3, n.3, p.165-177, 1997.

LE BRETON, Jean-Marie. Reflexões anglófilas sobre a geopolítica do inglês. In: LACOSTE, Yves; RAJAGOPALAN, Kanavillil. (Orgs.) A geopolítica do inglês. São Paulo: Parábola Editora, 2005. p. 12-26. 
LEFFA, Vilson J.. O professor de línguas estrangeiras: do corpo mole ao corpo dócil. In: FREIRE, Maximina M.; ABRAHÃO, Maria Helena Vieira; BARCELOS, Anna Maria Ferreira. (Orgs.) Lingüística aplicada e contemporaneidade. Campinas: ALAB-Pontes Editores, 2005. p. 203-218.

LOUSADA Eliane. Os pequenos grandes impedimentos da ação do professor: entre tentativas e decepções. In: MACHADO, Anna Rachel. (Org.) $\mathbf{O}$ ensino como trabalho: uma abordagem discursiva. Londrina: EDUEL, 2004. p. 271-296.

LLURDA, Enric. Non-native-speaker teachers and English as an international language. In: International Journal of Applied Linguistics, Oxford, v.14, n.3, 2004. p. 314-323.

MEDGYES, Peter. The non-native teacher. London: Macmillan Publishers Ltd., 1994.

MORROW, Raymond A.; TORRES, Carlos Alberto. Estado, globalização e políticas educacionais. In: BURBULES, Nicholas C.; TORRES, Carlos Alberto. Globalização e educação - perspectivas críticas. Porto Alegre: Artmed, 2004. p. 27-43.

NESBIT, Tom. Cultures of Teaching. Disponível em:

<http://www.edst.educ.ubc.ca/aerc/2000/nesbitt-final.PDF>. Acesso em: set. 2005.

OSLER, Audrey. Education for democratic citizenship: new challenges in a globalised world. In: OSLER, Audrey; STARKEY, Hugh. (Orgs.) Citizenship and language learning international perspectives. Stoke-on-Trent: Trentan Books, 2005. p. 3-22.

RAJAGOPALAN, Kanavillil. A geopolítica da língua inglesa e seus reflexos no Brasil - por uma política prudente e propositiva. In: LACOSTE, Yves; RAJAGOPALAN, Kanavillil. (Orgs.) A geopolítica do inglês. São Paulo: Parábola Editora, 2005. p. 135-157.

RINVOLUCRI, Mário. Glitches and poetry of non-native English. In: Modern English Teacher, London, v.14, n.2, Abril, 2005. p. 13-14. 
SAUJAT, Frédéric. O trabalho do professor nas pesquisas em educação: um panorama. In: MACHADO, Anna Rachel. (Org.) $O$ ensino como trabalho: uma abordagem discursiva. Londrina: EDUEL, 2004. p. 3-34.

SOUZA-E-SILVA, Maria Cecília Perez de. O ensino como trabalho. In: MACHADO, Anna Rachel. (Org.) $\mathrm{O}$ ensino como trabalho: uma abordagem discursiva. Londrina: EDUEL, 2004. p. 81-104.

SUAREZ-OROZCO, Marcelo M.; QIN-HILLARD, Desirée Baollan. Globalization: culture and education in the new millennium. In: SUAREZ-OROZCO, Marcelo M.; QIN-HILLARD, Desirée Baollan. (Eds.) Globalization: culture and education in the new millennium. Berkeley: University of California Press, 2004.

VOLPI, Marina Tazón. A formação de professores de língua estrangeira frente aos novos enfoques de sua função docente. In: LEFFA, Vilson J.. (Org.) O professor de línguas estrangeiras: construindo a profissão. Pelotas: Educat, 2001. p. 125-133.

ZEICHNER, Kenneth M.; TABACHNIK, B. Robert; DENSMORE, Kathleen. Individual, institutional and cultural influences on the development of teachers' craft knowledge. In: CALDERHEAD, James. (Org.) Exploring teachers' thinking. London: Cassell, 1987. p. 2159. 


\section{ANEXOS}

AUTORIZAÇÃo

QUESTIONÁRIO PARA PROFESSORES 


\section{AUTORIZAÇÃo}

O objetivo deste questionário é investigar a opinião de professores com relação a fatores que influenciam seu trabalho, aos conhecimentos necessários a esse trabalho e à própria formação profissional.

As informações obtidas fornecerão subsídios para a elaboração de um trabalho para a disciplina "Fatores institucionais e atuação docente no ensino de línguas" do Programa de Pós-Graduação em Estudos da Linguagem da Universidade Estadual de Londrina, e também para o desenvolvimento da dissertação de mestrado desta pesquisadora nesse mesmo programa.

Asseguramos aos participantes que as informações terão caráter confidencial e nenhum nome será mencionado em quaisquer publicações baseadas nos dados coletados. Esclarecemos que a autorização e identificação abaixo servem para cumprir com as exigências da ética científica e permitir a seleção de algumas pessoas para entrevista numa segunda fase desta pesquisa. Agradecemos sua colaboração e nos colocamos à disposição para esclarecimentos.

Gladys Quevedo Camargo

Londrina, outubro de 2005

$\mathrm{Eu}$, autorizo a mestranda Gladys

Quevedo Camargo a utilizar as informações fornecidas por mim neste questionário, e aceito ser contactado(a) para futura entrevista, caso necessário. Não autorizo, no entanto, a divulgação do meu nome em quaisquer publicações baseadas em dados coletados nesta pesquisa.

Local \& data:

Assinatura: 


\section{QUESTIONÁRIO PARA PROFESSORES}

1) Na sua opinião, existe alguma relação entre o tema ‘globalização’ e sua prática de sala de aula?

( ) Sim. Qual?

( ) Não.

2) Numere os fatores que, na sua opinião, influenciam de alguma forma seu trabalho como professor(a). Coloque 1 (mais importante); 2 (importante) ou 3 (menos importante).

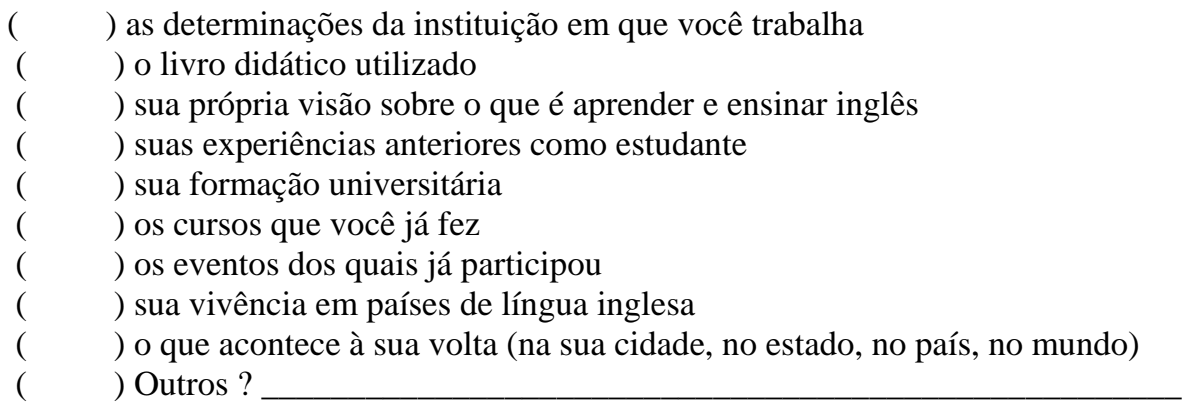

3) O seu conhecimento sobre ensinar inglês seria útil em outro contexto educacional (outra escola, cidade ou outro país)?

( ) Sim. Por que?

( ) Não.

4) Na sua opinião, quais são os conhecimentos mais importantes que devem ser dominados pelo professor de inglês, independentemente do seu contexto de trabalho? Coloque 1 (mais importante); 2 (importante) ou 3 (menos importante).
( ) metodologia
( ) pedagogia e didática
( ) a língua inglesa propriamente dita
( ) experiência prática de sala de aula
( ) vivência em países de língua inglesa
( ) Outros?

5) Na sua opinião, quais conhecimentos foram predominantes para que você fosse selecionado(a) para trabalhar na instituição em que você está? (assinale quantos forem necessários)
( ) seu conhecimento metodológico
( ) seu conhecimento didático-pedagógico
( ) seu conhecimento de língua inglesa
( ) suas experiências anteriores como professor(a)
( ) sua vivência em países de língua inglesa
( ) Outros? 